\title{
Antithrombotic medication and bleeding risk in patients with cerebral cavernous malformations: a cohort study
}

\author{
*David Bervini, MD, MAdvSurg, ${ }^{1}$ Christian Jaeggi, BMed, ${ }^{2}$ Pasquale Mordasini, MD, ${ }^{3}$ \\ Philippe Schucht, MD, ${ }^{1}$ and Andreas Raabe, MD'

\begin{abstract}
'Department of Neurosurgery, Inselspital, Bern University Hospital; '2University of Bern; and ${ }^{3}$ Department of Neuroradiology,
\end{abstract} \\ Inselspital, Bern University Hospital, Bern, Switzerland
}

\begin{abstract}
OBJECTIVE Cerebral cavernous malformations (CCMs) are frequently diagnosed vascular abnormalities. The hemorrhagic risk associated with the use of long-term antithrombotic medication (ATM) in patients with CCMs is a matter of controversy. The aim of this study was to determine the hemorrhagic risk associated with ATM use in patients diagnosed with one or more CCMs.
\end{abstract}

METHODS Demographic, clinical, treatment, and ATM-related information on patients diagnosed with one or more CCMs at a single institution over more than 34 years was retrospectively recorded. Univariate and multivariate descriptive and survival analyses were used to assess potential risk factors associated with CCM-related hemorrhage at presentation and during follow-up (first or subsequent hemorrhage).

RESULTS A total of 408 patients were included in the analysis and 492 CCMs were followed up after diagnosis, for a total of 1616 lesion-years. Thirty-seven (7.5\%) CCMs bled during follow-up, leading to an overall annual rate of CCMrelated symptomatic hemorrhage of $2.3 \%(95 \% \mathrm{Cl} 1.7 \%-3.2 \%)$. Eighty-two patients harboring $91 \mathrm{CCMs}(16.8 \%)$ were on ATM. When stratified for ATM, the annual rates of hemorrhage were $0.7 \%(95 \% \mathrm{Cl}<0.01 \%$ to $4.2 \%)$ for the lesions in patients on ATM versus $2.5 \%(95 \% \mathrm{Cl} 1.8 \%-3.4 \%)$ for those not on ATM. ATM was not found to be associated with either an increased risk of CCM-related hemorrhage at presentation $(p=0.355)$ or an increased risk of CCM-related hemorrhage (first or subsequent hemorrhage) in multivariate descriptive $(p=0.912)$ and survival $(p=0.145)$ analyses.

CONCLUSIONS The use of ATM does not seem to be associated with an increased risk of hemorrhage in patients diagnosed with CCMs.

https://thejns.org/doi/abs/10.3171/2018.1.JNS172547

KEYWORDS antithrombotic medication; brain; cerebral cavernous malformation; cavernoma; intracranial hemorrhage; vascular disorders

$\mathrm{C}$ EREBRAL cavernous malformations (CCMs), also known as cavernomas, cavernous angiomas, and cavernous hemangiomas, are frequently diagnosed intracranial vascular abnormalities of the brain. One in 5 patients has more than one $\mathrm{CCM},{ }^{12}$ and prevalence of these lesions in the general population is estimated to be $0.1 \%$ $0.5 \% .^{14,16,19}$ After intracranial aneurysms, CCMs are the second-most commonly diagnosed of all cerebral vascular malformations. ${ }^{8}$ CCMs consist of well-circumscribed, blood-filled channels of interconnected sinusoidal spaces, confined to nervous parenchyma only by a tunica interna. The lack of tight junctions contributes to the development of intrasinusoidal thrombosis, perilesional gliosis, and hemorrhage associated with CCMs. ${ }^{3}$
Wider access to diagnostic imaging has been associated with an increase in the number of patients incidentally diagnosed with one or more CCMs, ${ }^{19}$ while current demographic trends and the incidence of cardiovascular and cerebrovascular disease in the general population are responsible for an increasing number of patients being on long-term antiplatelet and/or anticoagulant medication. This raises the question of hemorrhagic risk and whether it is necessary to discontinue long-term antithrombotic medication (ATM) in patients diagnosed with one or more CCMs. Because earlier studies in small cohorts with limited follow-up ${ }^{4,6,17,18}$ have led to contradictory recommendations, large cohort studies are needed to answer this question. The aim of this study was to investigate the hem-

ABBREVIATIONS ATM = antithrombotic medication; $\mathrm{CCM}=$ cerebral cavernous malformation; $\mathrm{DVA}=$ developmental venous anomaly. SUBMITTED October 10, 2017. ACCEPTED January 10, 2018.

INCLUDE WHEN CITING Published online June 8, 2018; DOI: 10.3171/2018.1.JNS172547.

${ }^{*}$ D.B. and C.J. contributed equally to this work. 
orrhagic risk associated with the use of long-term ATM in patients diagnosed with one or more CCMs.

\section{Methods \\ Data Collection}

Data collection, analysis, and study design were approved and performed in accordance with our institutional ethics guidelines. Because of the retrospective nature of the data collection and analysis, specific consent of single patients was not considered to be required by our ethics commission. A database that collected records of consecutive patients diagnosed with a CCM was analyzed for the period from January 1980 to September 2015. The first authors (D.B. and C.J.) had the responsibility for review, extraction, and recording of all medical information in a computerized online database. The database contained demographic, clinical, radiological, and treatment-related information. Patients were included if they were confirmed to have one or more CCMs on MRI studies (including T1weighted, T2-weighted, FLAIR, T2*-weighted, and, since August 2009, susceptibility-weighted sequences) and/or CT scans reviewed by a neuroradiologist. Since the purpose of the study was to assess the risk of hemorrhage during follow-up, patients were excluded if they had only one contact date, if they were treated on the day of referral, or if they did not have a parenchymal CCM. All CCM lesions, irrespective of management plan, were included in the analysis. The initial date was taken as the earliest available date, either the date of referral, first consultation, or first radiological image confirming the diagnosis of CCM. CCM-related hemorrhage was defined as a new clinical event (focal deficit, seizure, or any acute or subacute onset of headache) in conjunction with radiological evidence (CT or MRI) of acute hemorrhage, or autopsy data suggesting acute hemorrhage. In the absence of such an event, the cases were censored at the earliest of the following: the first date of treatment (surgery), date of stopping ATM, or last follow-up. The CCM characteristics analyzed were as follows: 1) age (continuous variable); 2 ) sex; 3) history of high blood pressure; 4) long-term ATM use; 5) long-term antiplatelet medication use; 6) long-term anticoagulant medication use; 7) brainstem location; 8) CCM-related hemorrhage at presentation; 9) number of CCMs (i.e., one versus more than one); and 10) association with one or more developmental venous anomalies (DVAs).

\section{Statistical Analysis}

Descriptive statistics were used to report frequencies, means, ranges, and standard deviations. Continuous variables are presented as mean $\pm \mathrm{SD}$ of the means. For comparisons between any 2 groups, the Fisher exact test, Mann-Whitney U-test, and t-test were performed as appropriate.

From the outcome of these tests, the variables identified as significant were further analyzed by multiple logistic regression (backward Wald), calculating the single variable odds ratio, with $95 \% \mathrm{CI}$.

The rate of hemorrhage during follow-up was calculated as the number of new CCM-related hemorrhages (first or subsequent hemorrhage) during follow-up divided by the number of lesion-years of follow-up. The annual rate calculated was the percentage per lesion-year.

Univariate and multivariate Cox regression survival analyses were performed to estimate the hemorrhage risks and hazard ratio. Those variables found to be significant were further assessed using the Kaplan-Meier method. Time (days of follow-up) was used as the continuous variable and hemorrhage during follow-up as the event.

Statistical significance was established at the alpha level of $p=0.05$. Statistical analyses were performed using SPSS Package software (version 21, IBM).

\section{Results \\ Cohort Population}

Six hundred ninety-one patients met the criteria for radiological diagnosis of one or more CCMs. Of these, 96 were excluded because of lack of medical records and 187 because the diagnosis of CCMs was made only as part of the initial differential diagnosis and not confirmed by further radiological diagnostic imaging. A total of 408 consecutive patients, harboring $542 \mathrm{CCMs}$, were enrolled in our cohort and included in the analysis (Fig. 1). Follow-up was available for 492 lesions, for a total of 1616 lesionyears and a mean follow-up duration of $3.0 \pm 4.1$ years. Fifty $(9.2 \%)$ of 542 CCMs were seen only once and were therefore excluded from the survival analysis.

\section{Baseline Characteristics}

The mean age of patients at the time of CCM diagnosis was $48 \pm 18.9$ years (range $0-92$ years). Sex distribution was $47.0 \%$ female and $53.0 \%$ male. A single CCM was found in 353 patients $(86.5 \%$ ), and multiple CCMs were found in 55 patients (13.5\%). CCM-related hemorrhage at the time of diagnosis $(\mathrm{p}=0.355)$ and brainstem location $(p=0.378)$, both reported as being associated with an increased risk of CCM-related hemorrhage during followup,, 10 were equally distributed between the 2 subgroups of patients-those on ATM or not on ATM. Further data and characteristics of the 2 subgroups are provided in Table 1.

\section{Risk of Hemorrhage for All CCM Lesions}

One hundred thirty-six (25.1\%) CCM lesions presented with hemorrhage at the time of diagnosis, and 37 (7.7\%) bled (first episode or rehemorrhage) during follow-up, leading to an overall annual risk of hemorrhage of $2.3 \%$ (95\% CI 1.7\%-3.2\%). Seventy-two patients (73 [13.5\%] $\mathrm{CCM}$ lesions) were censored at the time of surgical treatment.

\section{Risk of Hemorrhage in the CCM Subgroup Not on ATM}

Three hundred twenty-six patients, harboring 451 CCMs (83.2\% of all cases), were not on long-term ATM. Four hundred fourteen $(91.8 \%)$ lesions were seen more than once and therefore included in the survival analysis. The total follow-up time in this subgroup was 1473 lesionyears. During follow-up, 36 CCM-related hemorrhages were registered, leading to an annual hemorrhage rate of $2.5 \%$ (95\% CI 1.8\%-3.4\%). Of those, 21 CCM-related 


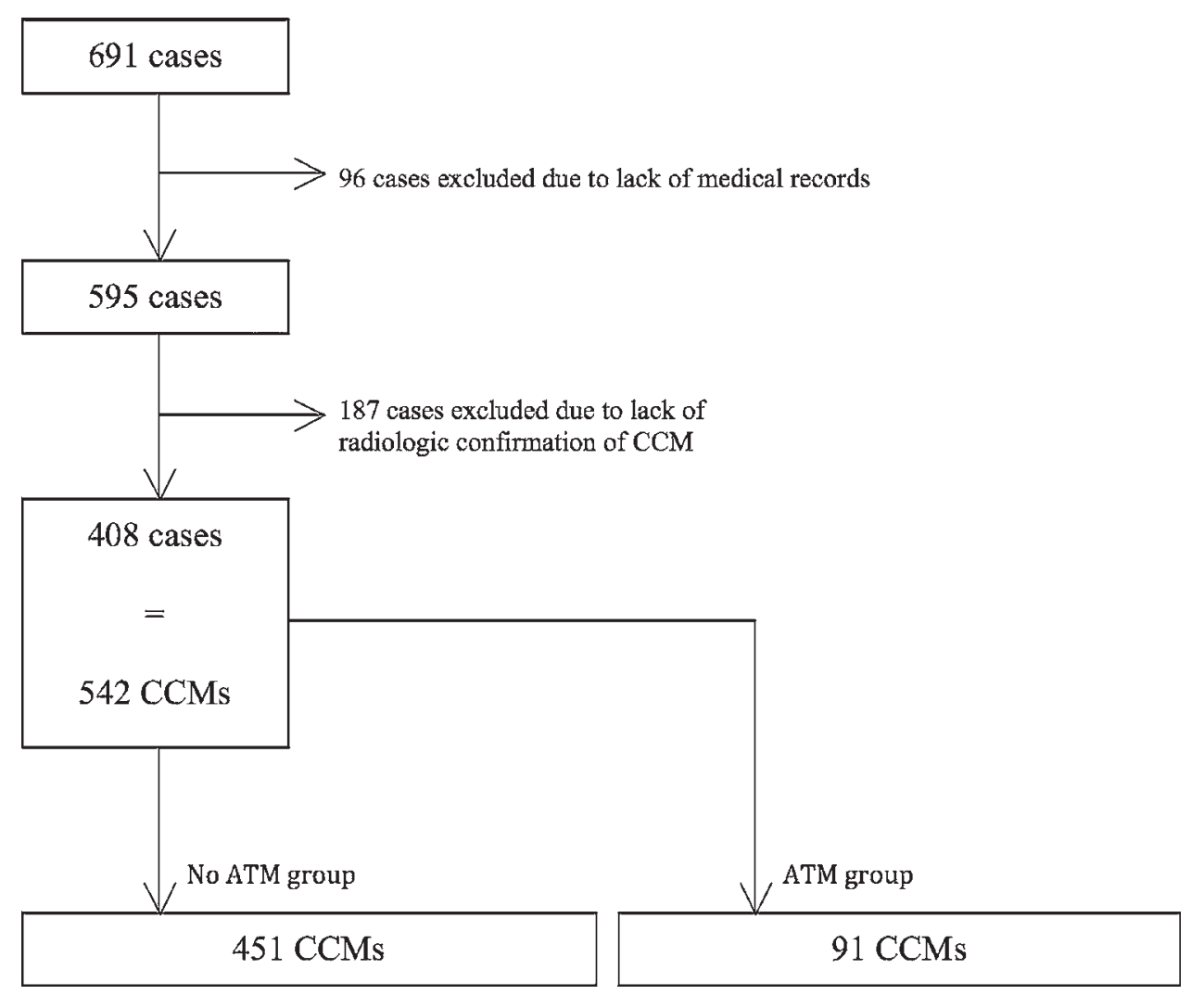

FIG. 1. Flowchart analysis.

hemorrhages were responsible for a new or worsened focal neurological deficit: 9 cases of sensorimotor impairment and/or aphasia, 3 cases of cerebellar symptoms, 2 cases of isolated cranial nerve palsy, 4 cases with new onset of seizure, and 3 cases with combined sensorimotor impairment and cranial nerve palsy.

\section{Risk of Hemorrhage in the CCM Subgroup on ATM}

Eighty-two patients, harboring 91 CCMs (16.8\% of all cases), were on long-term ATM for the treatment of concurrent cerebrovascular or cardiovascular disease: 74 $(13.7 \%)$ on antiplatelet medication and 17 (3.1\%) on anticoagulant medication. The indications for ATM were as follows: previous stroke and/or transient ischemic attack in 32 cases $(35.2 \%)$, cardiovascular diseases (i.e., atrial fibrillation and/or arrhythmia, cardiac ischemic disease, heart valve replacement, pulmonary thromboembolic disease, or peripheral arteriopathy) in 50 cases (54.9\%), and primary prevention in 9 cases $(9.9 \%)$. For the breakdown of the ATM dosing and posology, see Table 1. Seventyeight $(85.7 \%)$ lesions were seen more than once and therefore included in the survival analysis. Total follow-up time in this subgroup was 143.9 lesion-years of observation. During follow-up, only one patient without a history of hemorrhage presented with a CCM-related hemorrhage, leading to a crude annual hemorrhage rate of $0.7 \%(95 \%$ $\mathrm{CI}<0.01 \%$ to $4.2 \%$ ) in this group. No patient underwent surgical treatment. The patient who experienced hemorrhage was diagnosed with $2 \mathrm{CCMs}$, one located at the level of the brainstem and the other, asymptomatic, located in the frontal lobe. He was on anticoagulant medication for a mechanical cardiac valve and developed hemorrhage related to the brainstem-located CCM 5.5 years after the initiation of treatment with the vitamin $\mathrm{K}$ antagonist. The CCM-related hemorrhage caused permanent unilateral facial palsy.

\section{Characteristics Associated With CCM-Related Hemorrhage at Presentation}

Of the variables examined, age (OR 0.98; 95\% CI $0.972-0.993 ; \mathrm{p}=0.002)$, brainstem location (OR 2.03; 95\% CI 1.160-3.629; $\mathrm{p}=0.013$ ), multiple CCMs (OR 2.03; 95\% CI 1.241-3.311; $\mathrm{p}=0.005)$, and association with one or more DVAs (OR 0.39; 95\% CI 0.245-0.633; p < 0.001) were found to be statistically associated with CCM hemorrhage at presentation in both univariate and multivariate descriptive analyses. ATM, sex, and preexisting high blood pressure were not associated with CCM-related hemorrhage at presentation (Table 2).

\section{Characteristics Associated With CCM-Related Hemorrhage During Follow-Up}

Age (OR 0.97; 95\% CI 0.954-0.993; p = 0.009) and CCM location in the brainstem (OR 2.74; 95\% CI 1.194$6.296 ; p=0.014$ ) were the only variables significantly associated with CCM-related de novo hemorrhage during follow-up in both univariate and multivariate analyses. ATM, sex, preexisting high blood pressure, CCM-related hemorrhage at presentation, multiple CCMs, and concom- 
TABLE 1. Baseline characteristics of 408 patients with 542 cerebral CCMs

\begin{tabular}{|c|c|c|c|c|}
\hline Variable & Total, No. $(\%)$ & ATM, №. (\%) & No ATM, No. (\%) & $p$ Value \\
\hline No. of patients & 408 & $82(20.1)$ & $326(79.9)$ & \\
\hline Female sex & $192(47.0)$ & $27(32.9)$ & $165(50.6)$ & $<0.001$ \\
\hline Mean age, yrs & $48 \pm 18.9$ & $62 \pm 15.2$ & $46 \pm 18.4$ & $<0.001$ \\
\hline Lowest age & $0^{*}$ & 15 & $0^{*}$ & \\
\hline Highest age & 92 & 92 & 85 & \\
\hline No. of CCMs & $542(100)$ & $91(16.8)$ & $451(83.2)$ & \\
\hline \multicolumn{5}{|l|}{ Location } \\
\hline Supratentorial† & $404(74.5)$ & $62(68.1)$ & $342(75.8)$ & 0.146 \\
\hline Infratentorial & $138(25.5)$ & $29(31.9)$ & $109(24.2)$ & \\
\hline Frontal lobe & $135(24.9)$ & $19(20.8)$ & $116(25.7)$ & \\
\hline Parietal lobe & $46(8.5)$ & $8(8.8)$ & $38(8.4)$ & \\
\hline Temporal lobe & $95(17.5)$ & $13(14.3)$ & $82(18.2)$ & \\
\hline Occipital lobe & $29(5.4)$ & $3(3.3)$ & $26(5.8)$ & \\
\hline Basal ganglia or thalamus & $42(7.8)$ & $11(12.1)$ & $31(6.9)$ & 0.129 \\
\hline Centrum semiovale & $57(10.5)$ & $8(8.8)$ & $49(10.8)$ & \\
\hline Cerebellum & $73(13.5)$ & $21(23.1)$ & $52(11.5)$ & \\
\hline Brainstem & $65(12.0)$ & $8(8.8)$ & $57(12.6)$ & 0.378 \\
\hline No. of patients w/ a single CCM & $353(86.5)$ & $75(91.5)$ & $278(85.3)$ & $<0.001$ \\
\hline No. of patients w/ multiple CCMs & $55(13.5)$ & $7(8.5)$ & $48(14.7)$ & \\
\hline No. $w / 2$ & $30(7.4)$ & $5(5.1)$ & $25(7.6)$ & \\
\hline No. w/ 3-5 & $15(3.7)$ & $2(2.4)$ & $13(4.0)$ & \\
\hline No. w/ 6-11 & $10(2.5)$ & 0 & $10(3.1)$ & \\
\hline CCMs: initial presentation & & & & 0.355 \\
\hline No hemorrhage & $406(74.9)$ & $72(79.1)$ & $334(74.1)$ & \\
\hline Hemorrhage & $136(25.1)$ & $19(20.9)$ & $117(25.9)$ & \\
\hline Associated AVM & $2(0.4)$ & 0 & $2(0.4)$ & 1.000 \\
\hline Associated DVA & $94(17.3)$ & $16(17.6)$ & 78 (17.3) & 1.000 \\
\hline \multicolumn{5}{|l|}{ ATM (dosing) } \\
\hline Antiplatelet medication & - & $74(81.3)$ & - & \\
\hline Anticoagulant medication & - & $17(18.7)$ & - & \\
\hline Acetylsalicylic acid (100 mg/day) & - & $63(69.2)$ & - & \\
\hline Vitamin K antagonists (adapted to INR) & - & $15(16.5)$ & - & \\
\hline Clopidogrel (75 mg/day) & - & $11(12.1)$ & - & \\
\hline Heparin (2850 IE/day) & - & 1 & - & \\
\hline Rivaroxaban (10 mg/day) & - & 1 & - & \\
\hline Surgical treatment & $73(13.5)$ & 0 & $73(16.2)$ & $<0.001$ \\
\hline Seen more than once \& included in survival analysis & $492(90.8)$ & $78(85.7)$ & $414(91.8)$ & \\
\hline CCM-related hemorrhage during follow-up & $37(7.5)$ & $1(1.3)$ & $36(8.7)$ & \\
\hline Mean follow-up, yrs & $3.0 \pm 4.08$ & $1.6 \pm 2.17$ & $3.3 \pm 4.32$ & 0.001 \\
\hline Longest follow-up, yrs & 22.8 & 9.8 & 22.8 & \\
\hline Lesion-years of follow-up & 1616 & 144 & 1473 & \\
\hline Annual hemorrhage rate $(95 \% \mathrm{Cl}) \S$ & $2.3(1.7-3.2)$ & $0.7(<0.01-4.2)$ & $2.5(1.8-3.4)$ & \\
\hline
\end{tabular}

$\mathrm{AVM}=$ arteriovenous malformation; INR = international normalized ratio; $-=$ not applicable.

Values are presented as the number (\%) of patients or lesions unless otherwise specified.

${ }^{*} n=1$, diagnosis at 11 months.

† CCMs located in supratentorial lobar brain (frontal, parietal, temporal, occipital), basal ganglia, and thalamus.

$\ddagger$ Cerebellum- and brainstem-located CCMs.

$\S$ CCM-related follow-up hemorrhages divided by lesion-years of follow-up. 
TABLE 2. Characteristics of $542 \mathrm{CCMs}$ and association with hemorrhage at presentation

\begin{tabular}{|c|c|c|c|c|c|c|}
\hline \multirow[b]{2}{*}{ Variable } & \multicolumn{6}{|c|}{ CCM-Related Hemorrhage at Presentation } \\
\hline & No. of CCMs (\%) & $\begin{array}{l}\% \text { of Group Presenting } \\
\text { w/ Hemorrhage (no.) }\end{array}$ & $\begin{array}{l}p \text { Value } \\
\text { (univariate) }\end{array}$ & $\begin{array}{c}p \text { Value } \\
\text { (multivariate) }\end{array}$ & OR & $95 \% \mathrm{Cl}$ \\
\hline Age (continuous), yrs & $48 \pm 19$ & $46 \pm 19$ & 0.044 & 0.002 & 0.98 & $0.972-0.993$ \\
\hline Sex & & & 0.430 & - & - & - \\
\hline Male & $267(49.3)$ & $52.2(71)$ & - & - & - & - \\
\hline Female & $275(50.7)$ & $47.8(65)$ & - & - & - & - \\
\hline High blood pressure & $155(28.6)$ & $34.6(47)$ & 0.080 & - & - & - \\
\hline ATM & $91(16.8)$ & $14.0(19)$ & 0.355 & - & - & - \\
\hline Antiplatelet medication & $74(13.7)$ & $6.6(13)$ & 0.115 & - & - & - \\
\hline Anticoagulant medication & $17(3.1)$ & $4.4(6)$ & 0.392 & - & - & - \\
\hline Brainstem location & $65(12.0)$ & $17.6(24)$ & 0.022 & 0.013 & 2.03 & $1.160-3.629$ \\
\hline Multiple CCMs & $189(34.9)$ & $22.1(30)$ & $<0.001$ & 0.005 & 2.03 & $1.241-3.311$ \\
\hline Association w/ DVA & $94(17.3)$ & $26.5(36)$ & 0.002 & $<0.001$ & 0.39 & $0.245-0.633$ \\
\hline
\end{tabular}

Values are presented as the number (\%) of patients or lesions unless otherwise specified.

itance with DVA were not associated with CCM-related hemorrhage during follow-up (Table 3).

\section{Survival Analysis of Characteristics Associated With a Shorter Time to CCM-Related Hemorrhage During Follow-Up}

In both univariate and multivariate Cox regression survival analyses, age (HR 0.98; 95\% CI 0.959-0.996) and brainstem location (HR 2.83; 95\% CI 1.318-6.065) were the only variables associated with a shorter time to de novo CCM-related hemorrhage during follow-up. ATM (p $=0.145)$, antiplatelet medication $(\mathrm{p}=0.231)$, anticoagulant medication $(p=0.903)$, sex $(p=0.249)$, preexisting high blood pressure $(\mathrm{p}=0.634)$, CCM-related hemorrhage at presentation $(\mathrm{p}=0.239)$, multiple CCMs $(\mathrm{p}=0.112)$, and CCM's concomitance with DVA $(p=0.125)$ were not sig- nificantly associated with a shorter time to hemorrhage (Table 4). Kaplan-Meier curves were plotted for all lesions (Fig. 2), for 3 age categories (0-29 years, 30-59 years, 60 90 years; Fig. 3), and for CCMs located in the brainstem versus those that were not (Fig. 4).

\section{Discussion}

Cavernous malformations are mostly diagnosed incidentally in patients undergoing cerebrovascular imaging for stroke and other diseases. The present study, which included 408 consecutive patients diagnosed with 542 cavernous malformations, confirmed an annual CCM-related bleeding rate of $2.3 \%$. This is similar to the annual rates range of $0.3 \%-4.2 \%$ reported in the literature..$^{1,5,-11,15,17}$ To our knowledge, this is the largest consecutive patient cohort analysis on the topic reported to date.

TABLE 3. Characteristics and descriptive analysis of $492 \mathrm{CCMs}$ with a recorded referral date and subsequent date of hemorrhage or censoring*

\begin{tabular}{|c|c|c|c|c|c|c|}
\hline \multirow[b]{2}{*}{ Variable } & \multicolumn{6}{|c|}{ De Novo CCM-Related Hemorrhage } \\
\hline & $\begin{array}{l}\text { No. of } \\
\text { CCMs (\%) }\end{array}$ & $\begin{array}{l}\% \text { of Group Developing De Novo } \\
\text { CCM-Related Hemorrhage (no.) }\end{array}$ & $\begin{array}{l}p \text { Value } \\
\text { (univariate) }\end{array}$ & $\begin{array}{c}p \text { Value } \\
\text { (multivariate) }\end{array}$ & OR & $95 \% \mathrm{Cl}$ \\
\hline Age (continuous, in yrs, $\pm S D$ ) & $48 \pm 19$ & $38 \pm 17$ & 0.002 & 0.009 & 0.97 & $0.954-0.993$ \\
\hline Sex & & & 0.161 & - & - & - \\
\hline Male & $243(49.4)$ & $38.8(14)$ & - & - & - & - \\
\hline Female & $249(50.6)$ & $61.1(22)$ & - & - & - & - \\
\hline High blood pressure & $141(28.7)$ & $19.4(7)$ & 0.252 & - & - & - \\
\hline ATM & $78(15.8)$ & $2.8(1)$ & 0.029 & 0.912 & - & - \\
\hline Antiplatelet medication & $63(12.8)$ & $0(0)$ & 0.009 & 0.997 & - & - \\
\hline Anticoagulant medication & $15(3.0)$ & $2.8(1)$ & 1.000 & - & - & - \\
\hline Brainstem location & $61(12.4)$ & $25.0(9)$ & 0.031 & 0.014 & 2.74 & $1.194-6.296$ \\
\hline CCM-related hemorrhage at presentation & $128(26.0)$ & $30.5(11)$ & 0.555 & - & - & - \\
\hline Multiple CCMs & $181(36.8)$ & $41.7(15)$ & 0.591 & - & - & - \\
\hline Association with DVA & $90(18.3)$ & $25.0(9)$ & 0.268 & - & - & - \\
\hline
\end{tabular}

${ }^{*}$ Clinical review or treatment, whichever came first. 
TABLE 4. Characteristics and survival analysis of $492 \mathrm{CCMs}$ with a recorded referral date and subsequent date of hemorrhage or censoring*

\begin{tabular}{|c|c|c|c|c|c|c|}
\hline \multirow[b]{2}{*}{ Variable } & \multicolumn{6}{|c|}{ Survival Analysis } \\
\hline & $\begin{array}{c}\text { No. of } \\
\text { CCMs }(\%)\end{array}$ & $\begin{array}{l}\text { \% of Group Developing De Novo } \\
\text { CCM-Related Hemorrhage (no.) }\end{array}$ & $\begin{array}{c}p \text { Value } \\
\text { (Cox univariate) }\end{array}$ & $\begin{array}{c}\text { p Value } \\
\text { (Cox multivariate) }\end{array}$ & $\mathrm{HR}$ & $95 \% \mathrm{Cl}$ \\
\hline Age (continuous), yrs & $48 \pm 19$ & $38 \pm 17$ & 0.035 & 0.019 & 0.98 & $0.959-0.996$ \\
\hline Sex & & & 0.249 & - & - & - \\
\hline Male & $243(49.4)$ & $38.8(14)$ & - & - & - & - \\
\hline Female & $249(50.6)$ & $61.1(22)$ & - & - & - & - \\
\hline High blood pressure & $141(28.7)$ & $19.4(7)$ & 0.634 & - & - & - \\
\hline ATM & $78(15.8)$ & $2.8(1)$ & 0.145 & - & - & - \\
\hline Antiplatelet medication & $63(12.8)$ & $0(0)$ & 0.231 & - & - & - \\
\hline Anticoagulant medication & $15(3.0)$ & $2.8(1)$ & 0.903 & - & - & - \\
\hline Brainstem location & $61(12.4)$ & $25.0(9)$ & 0.017 & 0.008 & 2.83 & $1.318-6.065$ \\
\hline CCM-related hemorrhage at presentation & $128(26.0)$ & $30.5(11)$ & 0.239 & - & - & - \\
\hline Multiple CCMs & $181(36.8)$ & $41.7(15)$ & 0.112 & - & - & - \\
\hline Association with DVA & $90(18.3)$ & $25.0(9)$ & 0.125 & - & - & - \\
\hline
\end{tabular}

${ }^{*}$ Clinical review or treatment, whichever came first.

Our results showed that, for patients with one or more $\mathrm{CCMs}$, neither oral antiplatelet agents nor anticoagulant therapy was associated with an increased risk of hemorrhage at presentation or during follow-up. In line with pre- vious studies, ${ }^{7,17}$ our findings did not support the discontinuation of ATM in patients with coexisting cardiovascular or cerebrovascular disease. Furthermore, despite not reaching statistical significance, the rate of de novo hemorrhage of

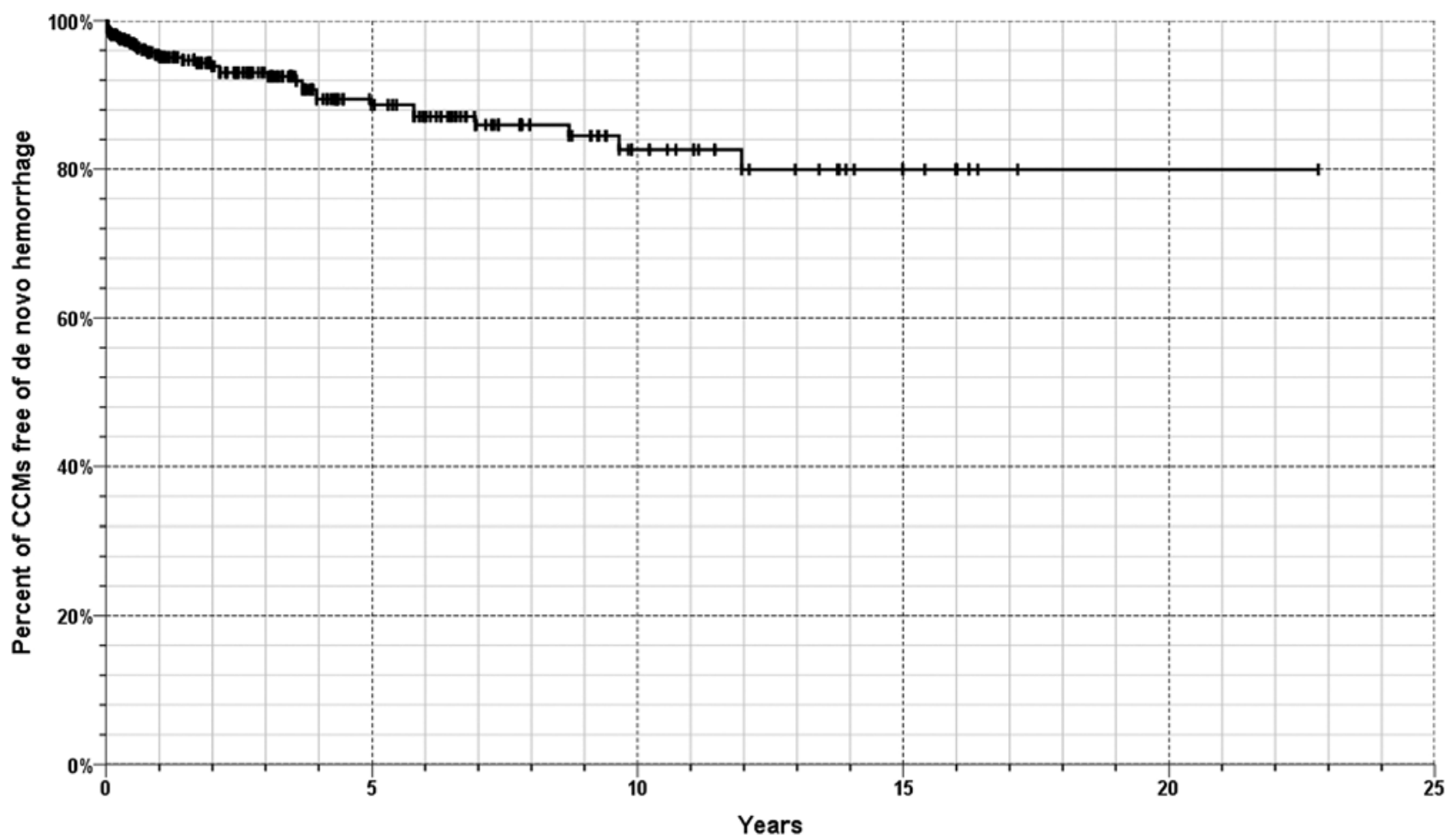

\begin{tabular}{|c|c|c|c|c|c|c|c|c|c|c|c|c|c|c|c|c|c|c|c|c|c|c|c|c|c|c|}
\hline Years & 鳏 & 1 & 2 & 3 & 4 & 5 & 6 & 7 & 8 & 9 & 10 & 11 & 12 & 13 & 14 & 15 & 16 & 17 & 18 & 19 & 20 & 21 & 22 & 23 & 24 & 25 \\
\hline $\begin{array}{c}\text { Number at } \\
\text { risk }\end{array}$ & 492 & 279 & 216 & 187 & 135 & 117 & 97 & 74 & 58 & 55 & 40 & 36 & 29 & 27 & 23 & 14 & 7 & 2 & 2 & 1 & 1 & 1 & 1 & 1 & 0 & 0 \\
\hline
\end{tabular}

FIG. 2. Kaplan-Meier curves and numbers at risk for 492 CCMs. 


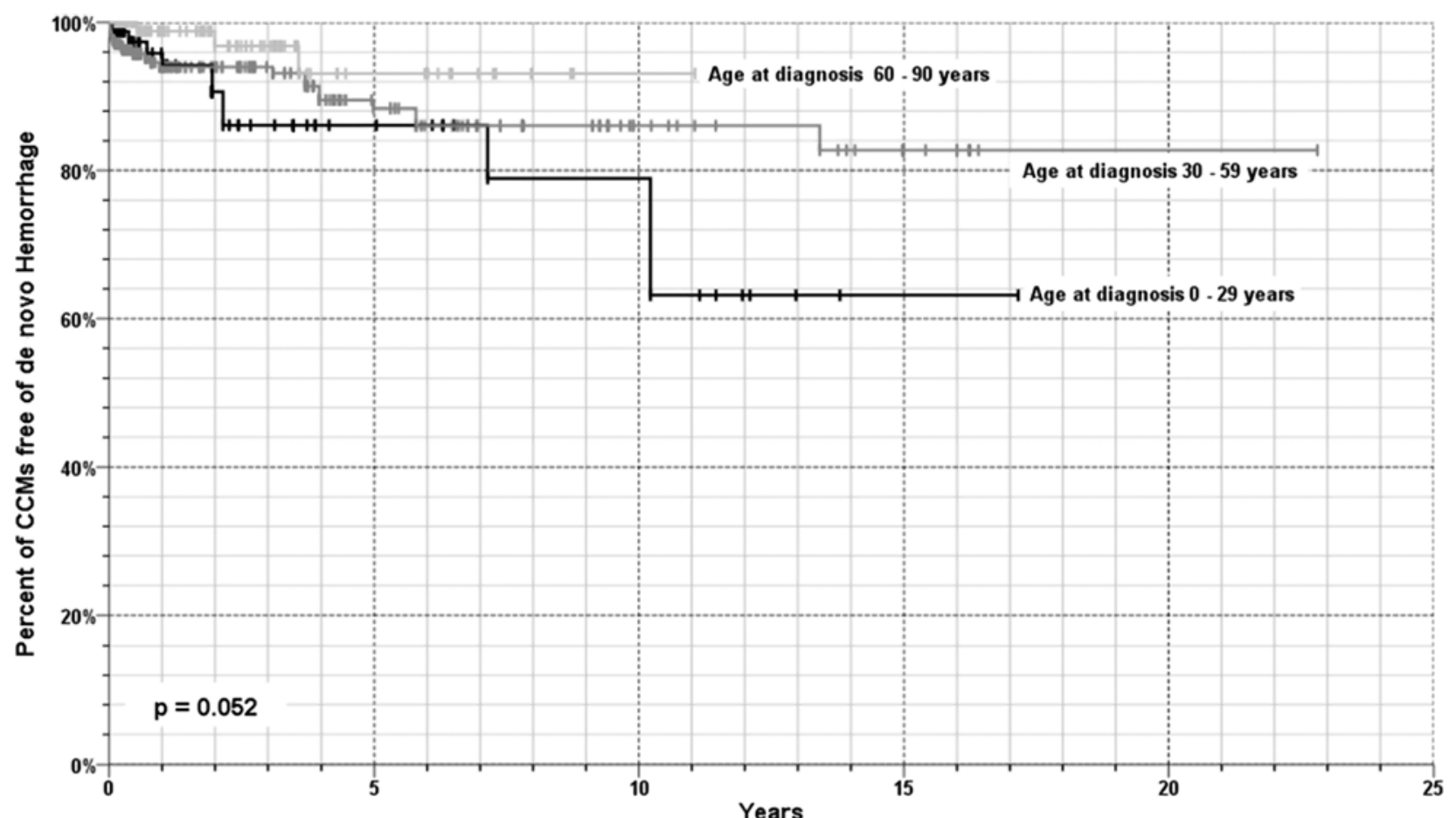

\begin{tabular}{|c|c|c|c|c|c|c|c|c|c|c|c|c|c|c|c|c|c|c|c|c|c|c|c|c|c|c|c|}
\hline & Years & 兽 & 1 & 2 & 3 & 4 & 5 & 6 & 7 & 8 & 9 & 10 & 11 & 12 & 13 & 14 & 15 & 16 & 17 & 18 & 19 & 20 & 21 & 22 & 23 & 24 & 25 \\
\hline \multirow{3}{*}{ 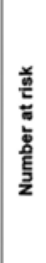 } & 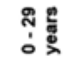 & 84 & 58 & 40 & 33 & 19 & 19 & 18 & 11 & 10 & 9 & 8 & 7 & 4 & 2 & 1 & 1 & 1 & 1 & 0 & 0 & 0 & 0 & 0 & 0 & 0 & 0 \\
\hline & 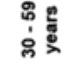 & 263 & 153 & 129 & 115 & 93 & 79 & 68 & 56 & 45 & 45 & 31 & 28 & 25 & 25 & 22 & 13 & 6 & 1 & 1 & 1 & 1 & 1 & 1 & 0 & 0 & 0 \\
\hline & $\begin{array}{l}80 \\
\vdots \\
\vdots \\
\vdots\end{array}$ & 145 & 68 & 47 & 39 & 22 & 19 & 11 & 7 & 3 & 1 & 1 & 1 & 0 & 0 & 0 & 0 & 0 & 0 & 0 & 0 & 0 & 0 & 0 & 0 & 0 & 0 \\
\hline
\end{tabular}

FIG. 3. Kaplan-Meier curves and numbers at risk for 492 CCMs grouped by age.

CCMs during follow-up seems to be lower for patients on ATM than for the cohort as a whole. In the present series, only one patient on anticoagulant medication, and none of those on antiplatelet medication, experienced a CCM-related symptomatic hemorrhage during a total of more than 140 lesion-years of follow-up, suggesting a crude single-lesion annual hemorrhage rate of $0.7 \%$ for patients on ATM.

In a descriptive analysis of a prospective cohort of 87 patients (16 on ATM medication), Schneble et al. found that no patient on ATM developed a de novo hemorrhage. ${ }^{17}$ Flemming et al. retrospectively reviewed a series of 292 patients diagnosed with one or more CCMs. Of those, only one of 40 patients on ATM developed a new symptomatic hemorrhage, representing a hemorrhage rate of $0.41 \%$ per person-year. ${ }^{6}$ Those findings and our results fit not only with the earlier hypothesis that ATM might not be associated with an increased risk of hemorrhagic events in patients with cavernous malformations, but also with the assumption that, by interfering with venous congestion, ATM might play a protective role in the pathophysiology of CCM hemorrhage.
Of all other variables examined in the descriptive and survival multivariate logistic regression analyses, brainstem location and younger age were the only ones associated with an increased risk of CCM-related hemorrhage, both at the time of presentation and during follow-up. CCM location in the brainstem is well known to be associated with hemorrhage during follow-up.,10 Age has previously been reported to be associated with CCM-related bleeding, ${ }^{2,13,15}$ but, despite being statistically significant, the odds ratio and hazard ratio for this variable are only slightly less than 1 , and their clinical significance should be interpreted with caution (Tables 2-4).

\section{Limitations}

Even though the characteristic profile at the time of CCM diagnosis (age, sex, hemorrhage at presentation, multiple CCM lesions, brainstem location, and concomitant DVA) was comparable to those previously reported in the literature, 9,10 our findings are subject to the well-documented methodological limitations associated with the 


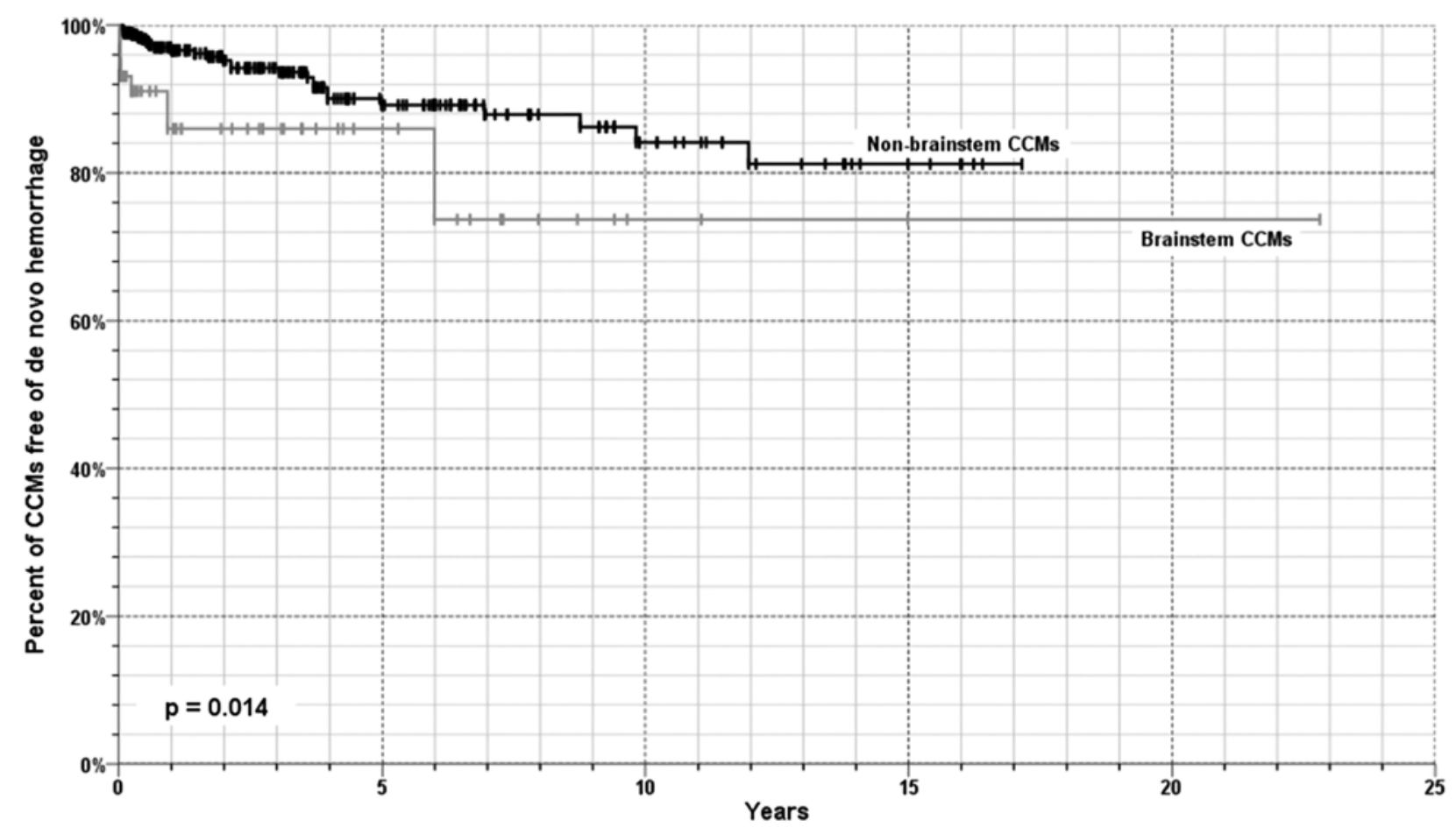

\begin{tabular}{|c|c|c|c|c|c|c|c|c|c|c|c|c|c|c|c|c|c|c|c|c|c|c|c|c|c|c|c|}
\hline & Years & 焉 & 1 & 2 & 3 & 4 & 5 & 6 & 7 & 8 & 9 & 10 & 11 & 12 & 13 & 14 & 15 & 16 & 17 & 18 & 19 & 20 & 21 & 22 & 23 & 24 & 25 \\
\hline \multirow{2}{*}{ 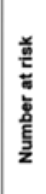 } & ๓๓ & 61 & 33 & 28 & 24 & 18 & 15 & 11 & 9 & 6 & 5 & 3 & 3 & 2 & 2 & 2 & 1 & 1 & 1 & 1 & 1 & 1 & 1 & 1 & 0 & 0 & 0 \\
\hline & 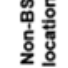 & 431 & 246 & 188 & 163 & 117 & 102 & 86 & 65 & 52 & 50 & 37 & 33 & 27 & 25 & 21 & 13 & 6 & 1 & 0 & 0 & 0 & 0 & 0 & 0 & 0 & 0 \\
\hline
\end{tabular}

FIG. 4. Kaplan-Meier curves and numbers at risk for 492 CCMs grouped by brainstem location versus other locations.

retrospective and single-center nature of our study. Furthermore, age, sex, CCM multiplicity, and surgical resection were not equally distributed between the subgroups of patients on ATM and not on ATM. These first 3 characteristics, however, have been reported not to be associated with an increased risk of hemorrhage during follow-up in 2 recently published studies - a pooled analysis ${ }^{9}$ and a meta-analysis ${ }^{17}$-and it is also possible that the effect of such a distribution might be minimized after performing multivariate analysis. However, CCM-related hemorrhage at presentation was found to be equally distributed between the subgroups of patients on ATM and those who were not. Because of the long period over which the data are reviewed, our cohort cannot be considered as representative of newer classes of anticoagulation medication. Finally, the limited mean follow-up of 3.0 years and its inequality between subgroups may be a potential source of bias. Considering the numbers at risk in our study at each stage of follow-up, we believe that our results should be interpreted with caution after the first 10 years of follow-up.

These limitations underline the need for a prospective, multicenter, population-based cohort study.

\section{Conclusions}

Our results suggest that the use of long-term ATM is not associated with an increased risk of spontaneous hemorrhage in patients diagnosed with one or more CCMs. Although our data are not statistically powered enough to substantiate a prophylactic effect of ATM in patients with $\mathrm{CCMs}$, they suggest that ATM, if otherwise indicated, should not be discontinued.

\section{References}

1. Al-Shahi Salman R, Berg MJ, Morrison L, Awad IA: Hemorrhage from cavernous malformations of the brain: definition and reporting standards. Stroke 39:3222-3230, 2008

2. Barker FGI II, Amin-Hanjani S, Butler WE, Lyons S, Ojemann RG, Chapman PH, et al: Temporal clustering of hemorrhages from untreated cavernous malformations of the central nervous system. Neurosurgery 49:15-25, 2001

3. Clatterbuck RE, Eberhart CG, Crain BJ, Rigamonti D: Ultrastructural and immunocytochemical evidence that an incompetent blood-brain barrier is related to the pathophysiology of cavernous malformations. J Neurol Neurosurg Psychiatry 71:188-192, 2001 
4. Connolly ES Jr: Cavernous malformations. J Neurosurg 118:42, 2013

5. El-Koussy M, Stepper F, Spreng A, Lukes A, Gralla J, Brekenfeld $\mathrm{C}$, et al: Incidence, clinical presentation and imaging findings of cavernous malformations of the CNS. A twentyyear experience. Swiss Med Wkly 141:w13172, 2011

6. Flemming KD, Link MJ, Christianson TJH, Brown RD Jr: Prospective hemorrhage risk of intracerebral cavernous malformations. Neurology 78:632-636, 2012

7. Flemming KD, Link MJ, Christianson TJH, Brown RD Jr: Use of antithrombotic agents in patients with intracerebral cavernous malformations. J Neurosurg 118:43-46, 2013

8. Greving JP, Wermer MJH, Brown RD Jr, Morita A, Juvela S, Yonekura M, et al: Development of the PHASES score for prediction of risk of rupture of intracranial aneurysms: a pooled analysis of six prospective cohort studies. Lancet Neurol 13:59-66, 2014

9. Gross BA, Lin N, Du R, Day AL: The natural history of intracranial cavernous malformations. Neurosurg Focus 30(6):E24, 2011

10. Horne MA, Flemming KD, Su IC, Stapf C, Jeon JP, Li D, et al: Clinical course of untreated cerebral cavernous malformations: a meta-analysis of individual patient data. Lancet Neurol 15:166-173, 2016

11. Kondziolka D, Monaco EA III, Lunsford LD: Cavernous malformations and hemorrhage risk. Prog Neurol Surg 27:141-146, 2013

12. Labauge P, Denier C, Bergametti F, Tournier-Lasserve E: Genetics of cavernous angiomas. Lancet Neurol 6:237-244, 2007

13. Lee JW, Kim DS, Shim KW, Chang JH, Huh SK, Park YG, et al: Management of intracranial cavernous malformation in pediatric patients. Childs Nerv Syst 24:321-327, 2008

14. Morris Z, Whiteley WN, Longstreth WT Jr, Weber F, Lee YC, Tsushima Y, et al: Incidental findings on brain magnetic resonance imaging: systematic review and meta-analysis. BMJ 339:b3016, 2009

15. Porter PJ, Willinsky RA, Harper W, Wallace MC: Cerebral cavernous malformations: natural history and prognosis after clinical deterioration with or without hemorrhage. J Neurosurg 87:190-197, 1997
16. Rigamonti D, Drayer BP, Johnson PC, Hadley MN, Zabramski J, Spetzler RF: The MRI appearance of cavernous malformations (angiomas). J Neurosurg 67:518-524, 1987

17. Schneble HM, Soumare A, Hervé D, Bresson D, Guichard JP, Riant F, et al: Antithrombotic therapy and bleeding risk in a prospective cohort study of patients with cerebral cavernous malformations. Stroke 43:3196-3199, 2012

18. Schwammenthal Y, Tanne D, Kurnik D: Letter by Kurnik et al regarding article, "antithrombotic therapy and bleeding risk in a prospective cohort study of patients with cerebral cavernous malformations". Stroke 44:e52, 2013 (Letter)

19. Vernooij MW, Ikram MA, Tanghe HL, Vincent AJPE, Hofman A, Krestin GP, et al: Incidental findings on brain MRI in the general population. N Engl J Med 357:1821-1828, 2007

\section{Disclosures}

The authors report no conflict of interest concerning the materials or methods used in this study or the findings specified in this paper.

\section{Author Contributions}

Conception and design: Bervini, Schucht, Raabe. Acquisition of data: Bervini, Jaeggi, Mordasini. Analysis and interpretation of data: Bervini, Jaeggi, Raabe. Drafting the article: Bervini, Jaeggi, Raabe. Critically revising the article: all authors. Reviewed submitted version of manuscript: all authors. Approved the final version of the manuscript on behalf of all authors: Bervini. Statistical analysis: Bervini, Jaeggi. Administrative/technical/material support: Raabe. Study supervision: Bervini, Raabe.

\section{Supplemental Information}

Previous Presentations

Portions of this work were presented in poster form at the EANS 2016, Athens, Greece, September 4-6, 2016.

\section{Correspondence}

David Bervini: Bern University Hospital (Inselspital), Bern, Switzerland.david.bervini@insel.ch. 